\title{
An Action Research Into Task-based CLIL Applied to Education Majors: From Chinese Students' Perspective
}

\author{
Huiying Liu \\ ${ }^{1}$ School of English and Education, Guangdong University of Foreign Studies, Guangzhou, China \\ Correspondence: Huiying Liu, School of English and Education, Guangdong University of Foreign Studies, \\ Guangzhou, China.
}

Received: December 30, 2018

Accepted: February 1, 2019 Online Published: February 2, 2019

doi: 10.5539/elt.v12n3p94

URL: https://doi.org/10.5539/elt.v12n3p94

\begin{abstract}
An action research (AR) was implemented to see if the proposed Task-based CLIL model is effective in achieving the dual goals of content and language learning among Chinese education majors. A questionnaire and a focus group interview were conducted to collect data from the students to see how they perceived the model with their own experience of it. According to the collected data, students stated that they had improved themselves in both English proficiency and subject content knowledge in addition to communication skills. They also stated that tasks offered them more language use opportunities to interact with peers discussing the disparities around task processes and outcomes in class. However, some problems were also identified, such as task organization, cultural conflicts and the choice of the right task. Reflecting on these problems, the teacher revised the teaching method, in which tasks are organized around the teacher's lectures and arranged according to their specific functions. This study can shed light on how CLIL can be successfully implemented in Chinese collegiate settings, which are different from those studies in non-Chinese contexts.
\end{abstract}

Keywords: task-based CLIL, tasks, action research, effectiveness

\section{Introduction}

CLIL is defined as a dual-focused educational approach in which an additional language is used for the learning and teaching of both content and language (Coyle et al., 2010). It developed in Europe in the mid-1990s as a response to the European Union's demands for multilingualism. The spread of this approach to other parts of the world is more related to the employment skills required for the new millennium, which include the solid specialized knowledge, high-level information literacy, and the ability to use language for communication in the field of both daily life and professional domains ( $\mathrm{Li}, 2006)$. Since CLIL was implemented in educational institutions at different levels, many positive learning outcomes have been reported in language learning, subject matter knowledge, cognition and cross-cultural awareness (Zarobe \& Catalan, 2009). Thanks to its great potentials to improve both language and content learning simultaneously, many language teachers are eager to borrow and try it in their classrooms. However, teachers are often overwhelmed by their difficult choice among a multitude of CLIL models, which comprise a wide range of potential models: single or dual, semi or complete immersion, translanguaging, modular thematic blocks and language showers (Lorenzo \& Moore, 2009). Grin (2005) identified 216 types of CLIL programs based on factors such as intensity, grade level of program onset, compulsory status, starting linguistic level and duration (Tedick \& Cammarata, 2012). As Coyle et al. (2010: 14) have pointed out that while there are lessons to be learned, ideas to be borrowed and developed based on existing models, one size does not fit all - there is no one model that fits all contexts. This indicates that teachers have to work out a model of their own or make changes to the established ones according to their own educational contexts. In this study, an attempt has been made to incorporate tasks into the 4C framework of CLIL to keep the integration and application of content and language. This paper aims at exploring the effectiveness of the Task-based CLIL model, which is employed to teach Chinese education major students the course, Sociology of Education, through action research.

\section{Theoretical Underpinnings}

\subsection{The 4C Framework of CLIL}

Traditional language teaching sees language learning as translating ideas in the mind with grammatical rules and 
target language vocabulary or as a linear process of input-processing-output (Stern, 1999; Ellis, 1999). As such, language learning is thought to involve learning about the language per se or following the simplified linear process. In fact, in learning another language, a number of other factors need to be taken into account such as communication skills, knowledge of subject matter, cultural awareness and cognitive processes. CLIL goes beyond such an atomist view of language learning and takes a holistic view of language learning. Coyle et al. (2010: 41) proposed a 4C framework integrating the four contextualized building blocks of language learning: content (subject matter), communication (language learning and using), cognition (learning and thinking processes) and culture (developing intercultural understanding and global citizenship). The strength of this framework is that it integrates content learning and language learning within specific contexts and acknowledges the symbiotic relationship that exists between these elements.

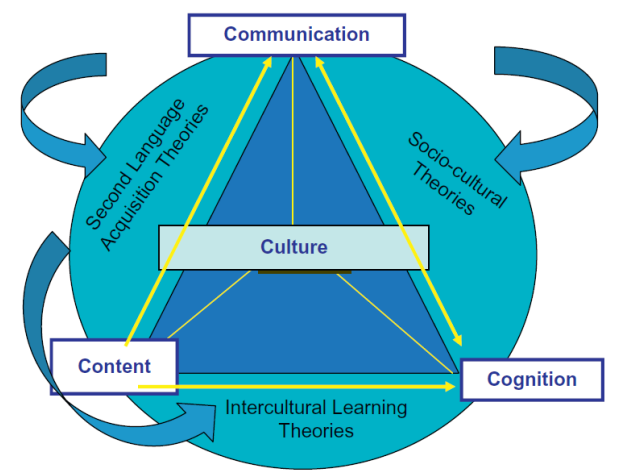

Figure 1. The 4Cs Framework of CLIL (Coyle, 2007)

In spite of its theoretical strength in integration, novice practitioners of this model, especially Chinese teachers, are rather confused about how they can get these components integrated and implemented in actual language teaching within subject matter courses. Coyle, as the original proponent of the $4 \mathrm{C}$ framework suggested that it need to be transformed into praxis. In this study, tasks are suggested as one way to the solution to this problem, since Chinese teachers are more familiar with Task-based Language Teaching (shortened as TBLT) than CLIL, as the Chinese national administrations of education has advocated since 2001 and TBLT has become a popular teaching method among language teachers. (English Curriculum Standards, Ministry of Education, 2001).

\subsection{Task-based Language Teaching}

TBLT is a language teaching model initiated in the late 1980s, and is featured by its focus on meaning construction and communicative use of language, a radical departure from the traditional language teaching with its sole focus on form. For TBLT, the focus is the accomplishment of tasks. According to Ellis (2013: 9), a task is a work plan that requires learners to process language pragmatically in order to achieve an outcome that can be evaluated in terms of whether the correct or appropriate proposition content has been conveyed. To this end, it requires learners to give primary attention to meaning and to make use of their own linguistic resources. The process of accomplishing a task can result in language use that bears a resemblance, direct or indirect, to the way language is used in the real world. A special strength of task is that it can integrate both productive and receptive skills as well as various cognitive processes at the same time.

\subsection{The Relationship Between CLIL and TBLT}

CLIL and TBLT have intrinsic relationship due to their departure from traditional view of language learning. Ortega (2015) pointed out the shared interests between CLIL and TBLT, both of which are based on the tenet that language and meaning are inseparable. Lyster (2015) not only made clear the connections between these two approaches to learning but also showed the connections between language and content learning in CLIL settings are strengthened while infusing the instructional design with key principles of TBLT.

The combination of CLIL and TBLT has made the tasks in CLIL contexts better facilitate subject-matter learning. Some of researchers have tried various tasks in different contexts. For example, Nikula (2015) tried academic language-as-action tasks in science classrooms, such as conducting and reporting on an experiment in chemistry and physics. Linares and Dalton-Puffer (2015) taught science through different formats like teacher-led whole-class discussion or group work discussion. Van Gorp and Van den Branden engaged learners in a teacher-scaffolding project for learning about DNA. The use of technology-mediated tasks is also 
implemented with multiple language and content learning objectives, such as teaching children to learn to think like an online game designer. In spite of the popular use of tasks, no attempt has been made to combine tasks into the $4 \mathrm{C}$ framework to make it a practical model for teachers to follow.

\subsection{A Tentative Proposal of Task-based CLIL}

Since the 1970s, many classroom interaction studies have demonstrated that teachers adopted the transmission mode of teaching, dominated classroom talk and left learners with little chances to give extended talk. (Van Gorp \& Van den Branden, 2015) Though much CLIL classroom practice involves learners as active participants in developing their potential for acquiring knowledge and skills through inquiry and problem solving (Coyle et al., 2010), classroom observations of seven schools, 40 lessons and 10 participating teachers by Dalton-Puffer (2007) show that the dominant activity type, by far, is teacher-led whole class discussion, featuring the typical IRF-pattern in long stretches of Triadic Dialogue. Longer stretches of coherent teacher talk is the classic lecture-type format for presenting curricular information. Therefore, if the lessons are planned or taught in order to transmit the knowledge points as in regular content instruction, students will be deprived of the chances to speak out or interact with their peers, which will inevitably be reversed to the 'banking model' of knowledge transmission, and is not helpful in developing students' autonomy and critical thinking (Freire, 1972).

A model combining tasks and the CLIL 4 C framework (See Figure 2) is proposed to resolve the problems of the dominant teacher-led lectures and few opportunities for language use commonly observed in CLIL classrooms. In this model, CLIL provides a reconceptualized view of language learning as a holistic endeavor, which means language learning should not be separated from content, cognition and cultural understanding. Tasks provide a means of how to get this approach implemented in practical teaching and achieve the goal of integration. Such a claim or hypothesis is made that subject content knowledge can be effectively and efficiently acquired by learners when tasks are incorporated into the $4 \mathrm{C}$ framework, and working through tasks can provide chances for learners' interaction, which can help them achieve the multiple purposes of learning.

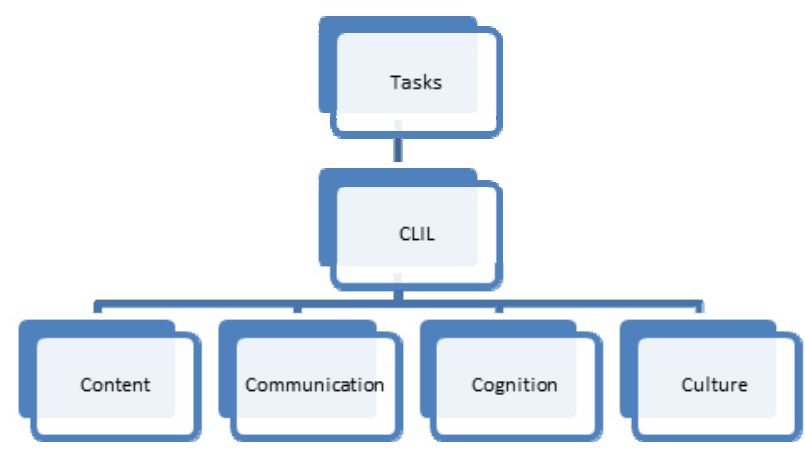

Figure 2. A Task-based CLIL framework

\section{Research Design}

\subsection{The Purpose and Research Questions}

In this study, two types of tasks are employed to help learners acquire knowledge of subject matter and learn to apply it into language production tasks. The first group of tasks, named as input tasks, consists of KWL charts, mind maps, summary writing. The second group of tasks, named as output tasks, consists of group presentations and term paper writing. As a matter of fact, input, output and interaction are all integrated while learners are engaged in accomplishing the tasks no matter whether they are engaged in input or output tasks. 


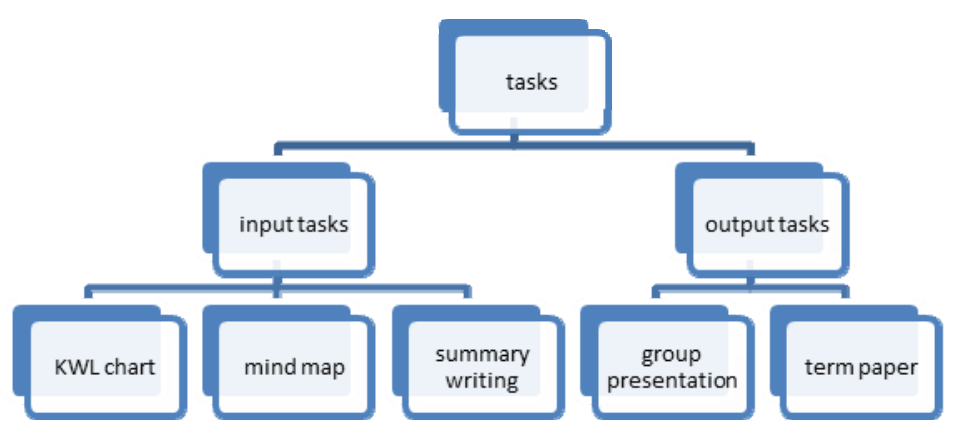

Figure 3. Task types in the task-based CLIL framework

The purpose of this study is to investigate the effectiveness of the proposed Task-based CLIL model from students' perspective, and try to answer the following research questions:

(1) What do students feel about the effectiveness of the model in terms of its general goal and its specific 4Cs?

(2) What are the strengths and weaknesses using the model to teach subject content knowledge in English?

(3) What are their suggestions on dealing with the weaknesses arising from classroom?

\subsection{Participants}

All the participants are the junior students from the 4 classes of English Language Education majors in a Chinese university in South China. Each class has around 25-27 students and most of them are girl students and boy students are minorities with 3-5 persons within each class. Most of them have passed the national test for English majors (TEM-4). When they graduate from university, a majority of them will be employed as English teachers by primary, secondary, or other educational institutions. The teacher (i.e. the author) taught the students Sociology of Education (SoE) in the spring semesters from February to July in the past few years. This course is aimed at helping students understand how social factors affect education, know about some theories of SoE, recognize and learn how to analyze educational issues related to social factors. It is mainly taught in English, but sometimes with the assistance of Chinese, mother tongue of both students and the teacher, to make necessary explanations or translations for better understanding. The teacher has been trained as an English language teacher and has worked in this post for over 20 years. During his postgraduate studies, he has been educated in the field of school curriculum and instruction, which has exposed him the professional knowledge and expertise in teaching SoE. But generally speaking, the author feels that his professional expertise is more leaned towards language teacher rather than subject matter teacher.

\subsection{A Two-part Action Research}

Action research (AR for short) is defined as any systematic inquiry conducted by teachers, administrators, counselors, or others with a vested interest in the teaching and learning process or environment for the purpose of gathering information about how their particular schools operate, how they teach, and how their students learn (Mill, 2007). According to this definition, people from various fields can conduct AR for their own purposes and into one's own practice (Johnson, 2008). But in educational settings, it is often done by teachers for the systematic improvement of their teaching. AR allows teachers to study their own classrooms, for example, to study their own instructional methods, students, and assessments, in order to better understand them and be able to improve the quality or effectiveness of teaching (Mertler, 2009).

The stages of conducting AR may vary but share the main steps. According to Kemmis and McTaggart (2000) AR consists of the following self-reflective cycles: 1) Planning in order to initiate change; 2) Implementing the change (acting) and observing the process of implementation and consequences; 3) Reflecting on processes of change and re-planning; 4) Acting and observing; 5) Reflecting (Kemmis \&Taggart, 2000). 


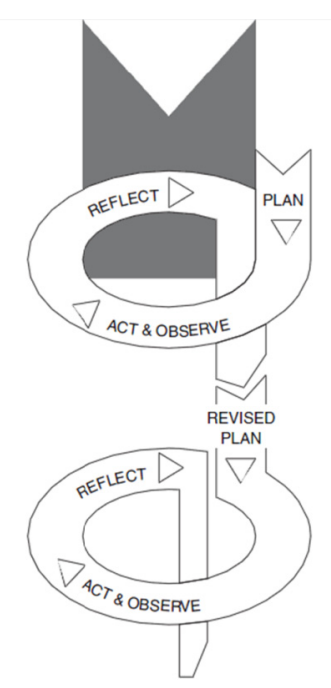

Figure 4. Stages in action research

This study is designed to follow the basic steps of AR. A two-part AR is designed to verify the effectiveness of the Task-based CLIL. The first part of the action research (AR1) involves the three tasks of KWL chart, mind map drawing, and summary writing, which are mainly employed to learn about subject content knowledge of SoE and get acquainted with the academic language associated with SoE. The second part of the action research (AR2) involves two consecutive tasks of oral presentations and term paper writing. In other words, oral presentations serve as a foundation for term paper writing. AR2 is intended to develop students' higher order cognitive skills and comprehensive use of language with the input gained from AR1.

\subsubsection{The First Part of Action Research (AR1)}

AR1 consists of three input-related tasks. The first task is a KWL chart, which is a graphical organizer designed to help learners in learning (Woolfolk, 2007). The letters KWL are an acronym, for what students already know, want to know, and ultimately learn in a lesson of the course. The KWL chart is often used as a form of instructional reading strategies that guides students through the reading of texts and stimulates learners to think and relate while reading. It is typically divided into three columns titled Know, Want and Learned.

\begin{tabular}{ccc}
\hline K & W & L \\
\hline What I know & What I want to know & What I learned \\
\hline
\end{tabular}

Figure 5. KWL chart

The second task is mind map drawing, which is used to visually organize information. It is often created around a single concept, written in the center of a blank page, to which associated ideas, concepts and theories are added. Major ideas are connected directly to the central concept, and other ideas branch out from those key ideas. The following figure is an exemplar of a mind map with mind map drawing guidelines at the center showing how to create a mind map. 


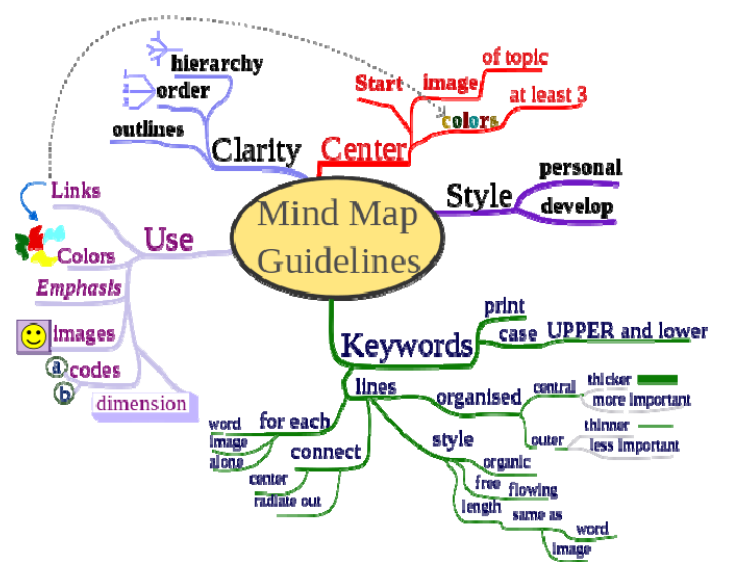

Figure 6. A mind map of mind map drawing guidelines

The third task is summary writing, which is a brief restatement of the main ideas of readings in learners' own words. It should include all the main and supporting points expressed in their own words in a condensed manner, and omit unnecessary details like examples, explanations and other unimportant information. It gives the same attention and stress to the points as the author does. As authors of the summary, students should not add their own ideas or comments on the topic. A summary is based on thorough understanding of the reading material, and is an integrated practice of reading, writing, and communication, if a chance is given to students for discussing the finished summary.

\subsubsection{The Second Part of Action Research (AR2)}

AR2 involves two consecutive output-related tasks of group presentations and term paper writing. Students are assigned in the second half of the semester to make oral presentations in groups and at the same time they are assigned the term paper writing task, which is expected to be finished by the end of the semester. At the very last week of the semester they are required to turn in their term papers as individual writing assignments.

An oral presentation is a widely used task, with which a student shows his/her knowledge on a particular subject. In this study, its main purpose is to practice academic spoken language by presenting subject content in a formal manner to a live audience, i.e. the teacher and peer classmates. Planning, writing and delivering are three key elements in making good oral presentation. The oral presentation is prepared and made in groups of 3 students. Students are suggested to choose their own topic — any educational issue in China from the perspective of SoE. Some of the topics are listed below:

- school choice

- off-campus training

- extracurricular activities

- unauthorized collection of fees by schools

- heavy after-school workload for pupils

- education of left-behind children of migrant farmers working in the cities

- the relationship between college enrollment expansion programs and unemployment

These topics are very important supplements to the textbook, since the textbook is written by American authors and only provides educational issues in America. By preparing and delivering an oral presentation on educational issues in China, students can have a comprehensive understanding of educational issues in local contexts and develop their cross-cultural understanding, specifically, the differences of educational issues between China and America.

A term paper is a relatively formal academic writing project written by students in a semester. In order to make students take term paper writing seriously, students were informed that it accounted for $15 \%$ of the final grade. Term paper writing is generally intended to argue for a point by using various sources on a particular subject. It is an individual assignment, which is written on the basis of the documentary research, but in this study, the oral presentation they have made forms a natural link with term paper writing and serves as a scaffold for students. 


\subsection{Instruments}

In this study, a questionnaire and a focus group interview (FGI for short) are the two research instruments used at the end of the semester to collect data about the research.

A questionnaire can help the researcher get three types of information at a time: factual or demographic, behavioral and attitudinal information (Burns, 2010). The questionnaire consists of 10 questions, which mainly involve students' attitude about the effectiveness of Task-based CLIL, the accomplishment of 4Cs, and the effectiveness of input and output related tasks.

FGI is an interview with a small group of people on a specific topic. Groups typically consist of six to eight people who participate in the interview for 90 to 120 minutes. Krueger and Casey (2000) pointed out that FGI is intended to make a group of people with specific attributes provide qualitative data related to the research topic in a comfortable environment, under the guidance of a moderator, and through group discussions. In this study, 8 students were invited to take part in the focus group interview; two from each of the four classes serve as representatives for each class. The interview questions are mainly about their perception of the Task-based CLIL, strengths and weaknesses of the model, problems encountered in learning and suggestions on how to improve teaching.

\section{Results}

\subsection{Results From the Questionnaire}

Prior to the end of the semester, a questionnaire was issued to students to collect their overall perception of the effectiveness of Task-based CLIL. A general question in it is concerned about their general experience of whether Task-based CLIL is an effective model for them to acquire both language and subject content knowledge of SoE; some specific questions are about whether they feel that they have improved in one aspect of the 4Cs, that is, content knowledge, communication, cognition and culture. Other questions are about the application of tasks in the process. 104 questionnaires were given out to the students and 96 were gathered as valid ones; those with all the same choice in one column or more were eliminated as invalid. A table about the responses and the percentage for each choice from the questionnaire is counted and given below.

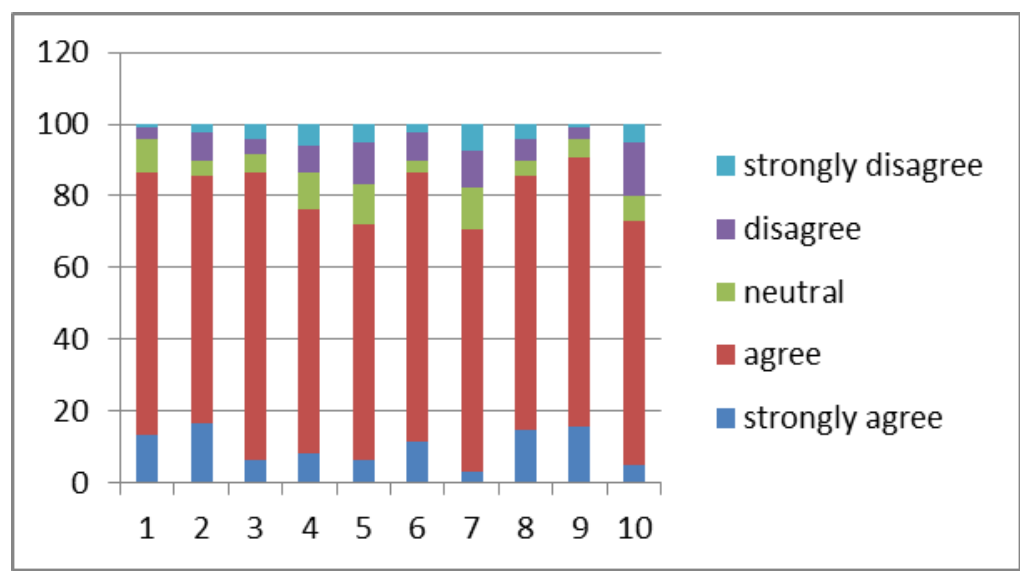

Figure 7. A graphic comparison of the different responses from the questionnaire

A graphic chart is made on the basis of the responses from the questionnaire so that a direct image has been created about how students responded to these questions. From the students' responses in the questionnaire, it can be found that the responses to questions $1,2,3,6,8$, and 9 with "strongly agree" and "agree" responses are more than 80 percent. The rest of the responses are over $70 \%$ positive. It can be concluded that students generally appreciate the model. For Question 1, the students gave an overall positive evaluation of the Task-based CLIL model. Questions 2 and 3 are concerned about the acquisition of content and knowledge. From the students' responses, they have perceived their improvement in these two areas. For Question 6, it is a general question about the use of tasks in this model, and responses are positive about the introduction of tasks in the learning process. Students acknowledge that both input-related tasks and output-related tasks have helped them with the improvement of language. But students' responses to input-related and output-related tasks differ, with output-related tasks having gained more positive responses. The last question is concerned with group work and 
73 per cent of the responses agree that group work affords them many opportunities to learn in the process.

\subsection{Results From the FGIs}

4.2.1 Results From the Application of the Input-Related Tasks

At the end of the semester, a group of 8 students were invited on voluntary basis for FGI to delve into their attitude to and personal experience with the use of the tasks. During the interview, the students were asked mainly the following three questions concerning the tasks:

(1) What are the strengths of each of the tasks used in class?

(2) What are the weaknesses of the tasks used in class?

(3) What suggestions would you offer to improve teaching using these tasks?

1) KWL chart

KWL chart is used before new content is introduced for preview or at the end of a chapter as a tool for reflection. The main purposes of this task are to activate students' prior knowledge about a topic and to have a reflection on what has been learned. Students' responses to the use of the chart in the FGI are summed up as follows: (S stands for student; Arabic number is only used for ordering responses from different students, but the same number may not be the same student)

The strengths of KWL chart mainly include its provision of many chances to process information in various ways and at different levels of depth. Many higher-order thinking skills are engaged in processing the reading chapters. Students' responses are positive in these aspects.

\section{S1: KWL chart increases the interaction between prior knowledge and new knowledge.}

S2: KWL presents information or knowledge concisely and visually.

S3: KWL can afford us chances to reflect on what has been learned.

S4: Interaction takes place while working on the chart.

S5: KWL can enhance the sorting out of the reading material.

The weaknesses of KWL chart do not lie in the use of the chart per se, but rather in students' previous knowledge of SOE and their perception of the use of tasks. For example,

S1: We have little prior knowledge about SoE, and some theories are hard to understand. Before we have a better understanding of the text about the theories, KWL chart does not show its assistance in learning.

S2: It is time consuming when we share the task outcomes, that is, when we report what we have filled in the chart.

Suggestions on how to improve the use of KWL chart mainly focus on how to coordinate the teacher's lecture and students' work on the KWL task. For example,

S1: We hope the teacher can give more lectures by making more explanation, making analysis and giving examples to show their applications.

S2: KWL chart might be better assigned after lectures so that students can give more reflection on what has been gained. Before we have got enough knowledge about SoE, the first two questions What I know, and What I want to know are difficult to capture.

S3: Before students are engaged in the task, they should be given one week or two weeks to prepare. Everyone in the group should be required to speak in class in case some students evade their duties in group work.

2) Mind map

Mind map drawing is a reading-focused task. Students are required to work in groups of 4-5 persons and work together to draw a mind map according to the assigned reading chapter from the textbook. After they finish their mind map, one student as representative will be called upon to illustrate their mind map.

Students are positive about the task of mind map drawing when it is combined with chapter reading. They have mentioned the following reasons for supporting the use of mind map when they are engaged in reading the textbook chapters.

S1: It can help me clarify the connection of ideas in reading and it can present the connection of ideas in a visual form, so it is easier to see the relationship between ideas.

S2: Drawing a mind map is a new form of reading task according to the contents of a chapter, and this can 
highly motivate students' interest.

S3: By drawing a mind map, students can have a better understanding of the contents in the chapter and get to know the relations between ideas.

S4: It can help express the mutual relationship between key ideas, and at the same time the hierarchical and cause and effect relationship can be clearly seen.

The weaknesses of mind map lie in the sharing the outcomes of the task and the appropriacy of using reading chapters for drawing a mind map.

S1: Since the reading text is rather academic, or maybe the speaker's English is not good enough, or their voice is not loud enough, when the speaker is making explanation about their mind map, sometimes I cannot follow the speaker very well. If my attention is distracted a little bit, I don't know what he/she is talking about.

S2: 1) Some sections of the reading are confusing and in disorder and it is difficult to draw a mind map. 2) Each group is largely concerned about the sections they are responsible for, so the group doesn't care much about the other sections.

S3: Some sections of the reading are not appropriate for drawing a mind map. I prefer to learn about the contents of these sections from the teacher, who can give clear and convincing explanation of the contents in these sections.

For the problems arising in the learning process, students suggest that the teacher give more guidance and check students' work.

S1: SoE is quite abstract and has a lot of stuff to deal with. If each individual student, rather than working in groups, is required to draw a mind map when we finish the study of the whole chapter, everyone will be clear about what they have learned.

S2: It is hoped that the teacher makes a summary of the main contents of the chapter and teaches it to the students after the students finish the mind mapping task.

S3: The teacher can give more guidance and feedback on how to improve it, and check the mind maps by every group.

3) Summary writing

To complete summary writing, students need to combine reading and writing. A good summary is based on students' reading comprehension, the ability to grasp the main ideas and distinguish main ideas from details. Students are assigned reading tasks for a chapter or section(s) of it and then write a summary on the basis of their reading. They can work individually or share the work for the reading assignment.

Students acclaim summary writing as an effective way to combine reading and writing, and keep track of the main ideas while reading. At the same time, group work on summary writing can lighten students' workload.

S1: Summary writing can help me better understand the contents of the chapter and reinforce my ability to generalize the main ideas of the chapter.

S2: Summary writing is a very good form of exercise and it connects reading and writing. It can help us accurately and quickly get grips with the main ideas of the chapter.

S3: Summary writing can better internalize the knowledge and make it part of our knowledge.

S4: We are overwhelmed by the large quantity of reading in each chapter. Summary writing by groups can tremendously reduce or lighten our reading.

In spite of the multiple advantages mentioned above, the weaknesses of summary writing are mainly found in how students from one group can manage to learn from other groups when they share the outcomes of their summaries.

S1: Since summary writing is a group work, each group is just focused on the section they are required to write the summary, so they tend to ignore the other sections in the chapter.

S2: Each group is responsible for writing a summary for one section of the chapter, so students would not spend time on the reading of the other sections. In class, we find it difficult to understand what other students share by talking about the main points in their summaries.

Students suggest that each individual student, instead of group work, be required to complete the task; they should be given sufficient time to read through the whole chapter. Some students also mention that the teacher 
should give more lectures on the content of each chapter. For example:

S1: I hope that the teacher gives us a detailed and thorough explanation of the structure and contents in the chapter.

S2: It would be better if the teacher makes a summary of the main ideas in the chapter and point out the key points and gives us a sample summary for reference.

\subsubsection{Results From the Application of the Output-Related Tasks}

1) Results from oral presentations

Oral presentation is a highly integrated learning task, which involves oral production, reading and writing activities. But the exercise of oral presentation in classroom is mainly used to serve the functions of improving oral language. In fact, a successful oral presentation depends to a large extent on the content and quality of the script. The rich content results from extensive reading while the quality of writing depends on the accuracy and rigorousness of academic language expression.

In this stage of $\mathrm{AR}$, students are required to make oral presentation on issues of Chinese education from the perspective of SoE. In order to make sure that the oral presentation can be successfully implemented, students are given 4 weeks on the preparation for it. The teacher keeps reviewing the topics, the outlines and the scripts for the oral presentation and provides necessary feedback on their rough script. Though presentation is challenging to most students, they have not tried to cover up the multiple strengths of it, and most of them are closely related to the development of higher-order cognition.

S1: It is a highly integrated task, which involves doing research, writing, critical thinking, collaborative teamwork.

S2: It can improve academic oral English addressed to an audience. In order to make a fluent speech, you have to practice a few times before the actual presentation.

S3: It can help to foster critical thinking skills in that when we have a discussion, different people may have different ideas, so we have to evaluate these ideas and decide upon the best ones.

The weaknesses of oral presentation mentioned by the students include large amount of time spent on it, lack of good integration of different sections, and little learning from peers.

S1: It is time consuming. For each presentation, you have to spend almost a week on it.

S2: Sometimes we can see that each member in a group is responsible for his or her own part(s), the presentation is not well integrated and ppt slides are not well edited.

S3: When students make oral presentation, I don't think I benefit a lot from their job.

As for how to gain more benefits from presentations, students suggest preparation for presentations ought to be process-oriented so that some interventions can be given at different stages, and presentation skills need to be honed.

S1: The teacher should get involved in the preparation process for the presentation.

S2: The students should report their development stages and what they have accomplished at each stage, so both the process and outcome should be emphasized.

S3: Three groups make their presentations at one time, so it is easier to see which group is doing the best.

S4: Presentation skills need to be improved so that the speakers and the audience can interact in one way or another, and the audience will be engaged in what the speakers are addressing.

2) Term paper writing

For most students, term paper writing is much more difficult than other forms of assignments. To reduce the difficulty involved in term paper writing, a connection is established between oral presentation and term paper and they are arranged in tandem to guarantee that the successful accomplishment of the first task can pave way for the second task. In addition, the teacher continues to provide feedback on students' topics, outlines and drafts for their paper.

The strengths of term paper writing can be shown in multiple aspects from students' response to the interview questions, such as integration of many skills, scaffolding function of earlier oral presentations and group work, and teacher's feedback.

S1: It is a very good exercise that integrates many different skills, such as the use of written language, critical 
thinking skills, and research skills.

S2: It provides a purpose for writing, so students have high motivation and interest to accomplish this task.

S3: Group oral presentation serves as very good scaffolding, which makes individual term paper writing much easier.

S4: The teacher's feedback on the outline and early drafts are very practical and to the point. Only by referring to the problems or mistakes in real writing can we have a better understanding and application of writing guidelines and theories.

S5: The teacher organizes the students into groups, and each member of the groups can help each other in terms of reviewing and feedback.

The weaknesses mainly lie in the facts that less time is available for students, the conflict between term paper writing and preparation for final exams. Students also mentioned the problems with the purpose of this task and the disconnection between the topic and the chapter topics in the textbook.

S1: We are not very clear about the purpose of term paper writing.

S2: The title or the topic of term paper is not in close connection with the topics in the textbook.

S3: The term paper is due at the last week of the semester, which is the time for students to review for the final exams. It would be better if the term paper is due a few weeks ahead so that students will not worry about the term paper and the final exams.

S4: Time spent on term paper writing is limited.

For the term paper writing task, students suggest that more guidance on term paper writing should be given, including writing techniques, choice of topics and format requirements.

S1: More guidance should be given right at the beginning of the term paper writing assignment.

S2: Students should be given freedom to choose their topics, rather than write the paper on the basis of oral presentations.

S3: The format of term paper should be clearly delineated, and some of us are not clear about what it is like.

\section{Findings and Reflection}

Overall, students are positive about the Task-based CLIL model for teaching a disciplinary subject in a foreign language. From the questionnaire, a large percentage of students gave positive responses to the model. From the FGI, more information has been collected about why and in exactly what aspects the model works, does not work or how it will work better.

First, Task-based CLIL is an effective model to integrate the 4Cs. From the results of the questionnaire and FGIs, students have improved themselves in subject content knowledge, language, cognition and intercultural understanding. Though the instructional medium is not the students' mother tongue, almost none of the students have complained about the inefficiency of subject content learning. Despite being exposed to new concepts and theories, they can still manage to obtain the subject content as required. Students in the FGI mentioned that the most obvious gain is the increase of academic vocabulary of the subject. SoE, as a new subject for students, contains a lot of new terms, concepts, theories, all of which are made into their vocabulary. Cognition is rather implicit and difficult to assess. However, in the process of completing tasks, many higher-order cognitive skills are engaged, rather than, rote memorization of discrete facts and points of language. Cross-cultural understanding lies in two facets: 1) by reading the textbook, students learned a lot about American educational system and its issues, and the social factors that affect American education. 2) It is natural to make a comparison and contrast between American and Chinese education when the two systems are placed side by side, by means of which students developed their cross-cultural understanding, which is in alignment of the principle of contrastivity (Wolff, 2011).

Second, the problems in the application of this model mainly arise from task organization, cultural conflict and the choice of the right task. In terms of task organization, input tasks and output are arbitrarily separated into two phases, in which input tasks precede output ones. It is assumed that students need to be exposed to some essential subject content before taking on output tasks. The rigid arrangement can be more flexible and new tasks are introduced before students get to grips with old ones, for students are overwhelmed with the number and varieties of tasks. Cultural conflicts here mainly refer to the fact that students may not be accustomed to a teaching model borrowed from Western countries. There are many times when students express their wishes that the teacher gave more lectures, checked their assignments and gave more guidance on term paper writing. To 
some extent, this is a cross-cultural issue. Chinese students are educated in an exam-oriented and teacher-led environment. In their learning, they seek for definitive answers and authoritative voice. Otherwise, they feel insecure and ill at ease. By using Task-based CLIL, students have to take on more responsibilities for their learning, but they are not used to turning to reference books and peers for help, instead they show their psychological reliance on the teacher. Another point to consider is that a pure task-based syllabus may not be suitable for Chinese students. According to students' responses, task-supported syllabus may fit better with Chinese students. (Ellis, 2013) Task-supported syllabus means that tasks are incorporated into regular approaches to teaching instead of a task-based syllabus. The third point to be reflected on is that some students complained that some input tasks are not fit for the reading assignments. As a matter of fact, all the three input tasks are used for getting the main ideas of the reading assignments but differ in their focus. These tasks have posed great challenges to the exam-oriented reading tradition with some multiple choice questions at the end of reading passages. Some students found that the logic in the textbook was not very good and sometimes the authors did not provide examples to illustrate some points. Without regard to the truth of this statement, this is a very good indication that students are deeply engaged in reading.

Third, students' learning styles ought to be changed. It takes some time for students to adapt themselves to the Task-based CLIL, because all the tasks are borrowed from abroad, and they are not popularly used in mainstream teaching in China. Generally speaking, Chinese students are more accustomed to lectures given by the teacher. They believe teachers are more professional and authoritative in subject knowledge, and they prefer to being exposed to the processed and definite information delivered by the teachers from the textbook. In addition, students still have not developed their autonomy in their study. Quite a few responses from the FGI indicate directly that they place much dependence on the teacher. As junior students, they should have developed their own ways of making use of various sources for learning. Most students rely too heavily on the single textbook rather than going to the library and read more reference books. Finally, students don't care much about learning from their peer students. When students deliver their presentation or talk in the discussion, some students just think it is their duty to complete the task rather than seeing it as a learning opportunity. Thus, peer learning needs to be advocated and fostered.

\section{Revised Plan}

According to the feedback data collected from students, in the next round of the AR, a revised teaching plan can be made in the following ways in order to address the problems arising in this round of AR. First, the teacher's lectures is arranged to precede the assignment of the tasks to give students an overview of each of the reading chapters. Tasks are important in developing students' abilities in many areas but they cannot replace the important role of the teacher and lectures in the classroom. (Dafouz et al., 2007) Secondly, the tasks can be arranged according to their specific functions. The input tasks can run through the whole semester to stimulate students' prior knowledge and give a purpose for their reading. The output-related tasks are more complex and time-consuming. These two tasks can be assigned at the early stage of the semester so that more guidance can be given and the preparation process can be better monitored. The teacher should focus on the requirements and guidelines for the tasks to make sure that students know what they are expected.

\section{Conclusions and Implications}

In this study, an action research is employed to see if the proposed Task-based CLIL is an effective means of teaching subject content in English. Data from the questionnaire show that students as the main stakeholders hold positive attitude towards the effectiveness of this model in both their personal experience of the model and some specific areas like subject content, language and cognitive development, and cross-cultural understanding. Data from the FGI indicate the benefits and problems underlying in the implementation of this model. In terms of the benefits, students stated that they had developed not only the 4Cs but also other skills, such as critical thinking, problem solving, and communications skills. The three input-related tasks effectively help students gain the disciplinary content from the reading assignments and make clear about the relationship between the main ideas. The two output-related tasks help them move up to a higher level of cognition. Students' attention has shifted away from the learning of language per se to explore the deeper meaning and relationship. In spite of the multiple benefits displayed, this research does not intend to make generalizations about its effect in other situations. It works in this situation and may not work in other situations. The most important implication of this research is that with the emerging new ideas, teaching models and theories, teachers can take bold steps in introducing them into their classroom and follow action research to make improvements in teaching with a theoretical framework and some solid evidence. Last but not least, limitations of this study should not be ignored. One is that this AR is only one round of the teaching practice and two rounds or more may be more convincing to prove its effectiveness. The other is that tasks are used to integrate content and language learning, but planned 
language learning exercises are not committed to due to the fact that too many things need to be attended to in teaching.

\section{Acknowledgments}

This study has been supported by the project (16BYY193) "The socio-cognitive approach to metapragmatic utterances in BELF interactions", funded by the National Planning Office of Philosophy and Social Science, P. R. China.

\section{References}

Burns, A. (2011). Doing action research in English language teaching: A guide for practitioners. Beijing: Foreign Language Teaching and Research Press.

Coyle, D., Hood, P., \& Marsh, D. (2010). CLIL: Content and Language Integrated Learning. Cambridge: Cambridge University Press.

Coyle, D. (2007). The CLIL quality challenge. In D. Marsh, \& D. Wolff (Eds.) Diverse Contexts-Converging Goals: CLIL in Europe. Oxford: Peter Lang.

Coyle, D. (2007). Content and language integrated learning: Towards a connected research agenda for CLIL pedagogies. International Journal of Bilingual Education and Bilingualism, 10(5), 543-562. https://doi.org/ $10.2167 /$ beb459.0

Dafouz, E., Núñez, B., \& Sancho, C. (2007). Analysing stance in a CLIL university context: Non-native speaker use of personal pronouns and modal verbs. International Journal of Bilingual Education and Bilingualism, 10(5), 647-662. https://doi.org/10.2167/beb464.0

Dalton-Puffer, C. (2007). Discourse in content and language integrated learning (CLIL) classrooms. Amsterdam: John Benjamins Publishing Company. https://doi.org/10.1075/11lt.20

Ellis, R. (1999). Understanding second language acquisition. Shanghai: Shanghai Foreign Language Education Press. https://doi.org/10.1017/S0272263199002077

Ellis, R. (2013). Task-based language learning and teaching. Shanghai: Shanghai Foreign Language Education Press.

Freire, P. (1972). Pedagogy of the oppressed. New York: Herder and Herder.

Kemmis, S., \& McTaggart, R. (2000). Participatory action research. In N. K. Denzin \& Y. S. Lincoln (Eds.), Handbook of qualitative research. Thousand Oaks, CA: Sage.

Krueger, R. A., \& Casey, M. A. (2000). Focus groups: A practical guide for applied research. Thousand Oaks, CA: Sage.

Li, B. L. (2006).An introduction to content-based second language teaching and learning. In M. Haley \& T. Y. Austin (Eds.), Content-based second language teaching and learning: An interactive approach. Beijing: World Book Publishing House.

Lorenzo, F., Casal, S., \& Moore, P. (2009). The effects of content and language integrated learning in European education: Key findings from the Andalusian bilingual sections evaluation project. Applied Linguistics, 31(3), 418-442. https://doi: 10.1093/applin/amp041

Mertler, C. A. (2009). Action research: teachers as researchers in the classroom. Thousand Oaks: SAGE Publications, Inc.

Mind Map. (2015). Retrieved from https://en.wikipedia.org/wiki/Mind_map\#/media/File:MindMap Guidlines.svg

Nikula T. (2015). Hands-on tasks in CLIL science classrooms as sites for subject-specific language use and learning. System, 54, 14-27. https://doi.org/10.1016/j.system.2015.04.003

Ortega, L. (2015). Researching CLIL and TBLT interfaces. System, 54, 103-109. https://doi.org/10.1016/j.system. 2015.09.002

Stern, H. H. (1999). Fundamental concepts of language teaching. Shanghai: Shanghai Foreign Language Education Press.

Tedick, D. J., \& Cammarata, L. (2012). Content and language integration in K-12 Contexts: Student outcomes, teacher practices, and stakeholder perspectives. Foreign Language Annals, 45(S1), 28-53. https://doi.org/ 10.1111/j.1944-9720.2012.01178.x 
Van Gorp, K., \& Van den Branden, K. (2015). Teachers, pupils and tasks: The genesis of dynamic learning opportunities. System, 54, 28-39. https://doi.org/10.1016/j.system.2015.04.018

Wolff, D. (2011). Content and language integrated learning. In K. Knapp, \& B. Seidlhofer (Eds.), In cooperation with Henry Widdowson. Handbook of foreign language communicatin and learning. New York: De Gruyter Mouton.

Woolfolk, A. (2007). Educational psychology (10th ed.). Beijing: China Light Industry Press.

Zarobe, Y. R., \& Catalan, R. M. J. (2009). Content and language integrated learning: Evidence from research in Europe. Bristol: Multilingual Matters. https://doi.org/10.21832/9781847691675

\section{Appendix}

Data from the questionnaire

\begin{tabular}{|c|c|c|c|c|c|c|c|c|c|c|}
\hline \multirow[t]{2}{*}{ Items/attitudes } & \multicolumn{2}{|c|}{$\begin{array}{l}\text { strongly } \\
\text { agree }\end{array}$} & \multicolumn{2}{|c|}{ agree } & \multicolumn{2}{|c|}{ neutral } & \multicolumn{2}{|c|}{ disagree } & \multicolumn{2}{|c|}{$\begin{array}{l}\text { strongly } \\
\text { disagree }\end{array}$} \\
\hline & no. & $\%$ & no. & $\%$ & no. & $\%$ & no. & $\%$ & no. & $\%$ \\
\hline $\begin{array}{l}\text { 1. Task-based CLIL is an effective model } \\
\text { of teaching. }\end{array}$ & 16 & 16.6 & 66 & 68.7 & 4 & 4.2 & 8 & 8.3 & 2 & 2.0 \\
\hline $\begin{array}{l}\text { 2. Task-based CLIL is conducive to my } \\
\text { improvement of language. }\end{array}$ & 13 & 13.5 & 70 & 72.9 & 9 & 9.4 & 3 & 3.1 & 1 & 1.0 \\
\hline $\begin{array}{l}\text { 3. Task-based CLIL is conducive to my } \\
\text { learning of subject knowledge }\end{array}$ & 6 & 6.3 & 77 & 80.2 & 5 & 5.2 & 4 & 4.2 & 4 & 4.2 \\
\hline $\begin{array}{l}\text { 4. Task-based CLIL involves many } \\
\text { cognitive activities. }\end{array}$ & 8 & 8.3 & 65 & 67.7 & 10 & 10.4 & 7 & 7.3 & 6 & 6.3 \\
\hline $\begin{array}{l}\text { 5. Task-based CLIL improves my } \\
\text { cross-cultural understanding }\end{array}$ & 6 & 6.3 & 63 & 65.6 & 11 & 11.5 & 11 & 11.5 & 5 & 5.2 \\
\hline $\begin{array}{l}\text { 6. Tasks play an important role in the } \\
\text { learning process }\end{array}$ & 11 & 11.5 & 72 & 75.0 & 3 & 3.1 & 8 & 8.3 & 2 & 2.1 \\
\hline $\begin{array}{l}\text { 7. Input tasks can help us gain knowledge } \\
\text { of the subject. }\end{array}$ & 3 & 3.1 & 65 & 67.7 & 11 & 11.5 & 10 & 10.4 & 7 & 7.3 \\
\hline $\begin{array}{l}\text { 8. Output tasks can help us integrate and } \\
\text { apply the knowledge gained. }\end{array}$ & 14 & 14.6 & 68 & 70.8 & 4 & 4.2 & 6 & 6.3 & 4 & 4.2 \\
\hline $\begin{array}{l}\text { 9. Both input tasks and output tasks have } \\
\text { helped us with the improvement of } \\
\text { language. }\end{array}$ & 15 & 15.6 & 72 & 75 & 5 & 5.2 & 3 & 3.1 & 1 & 1.0 \\
\hline $\begin{array}{l}\text { 10. Group work affords us many } \\
\text { opportunities to learn in the learning } \\
\text { process. }\end{array}$ & 5 & 5.2 & 65 & 67.7 & 7 & 7.3 & 14 & 14.6 & 5 & 5.2 \\
\hline
\end{tabular}

\section{Copyrights}

Copyright for this article is retained by the author(s), with first publication rights granted to the journal.

This is an open-access article distributed under the terms and conditions of the Creative Commons Attribution license (http://creativecommons.org/licenses/by/4.0/). 